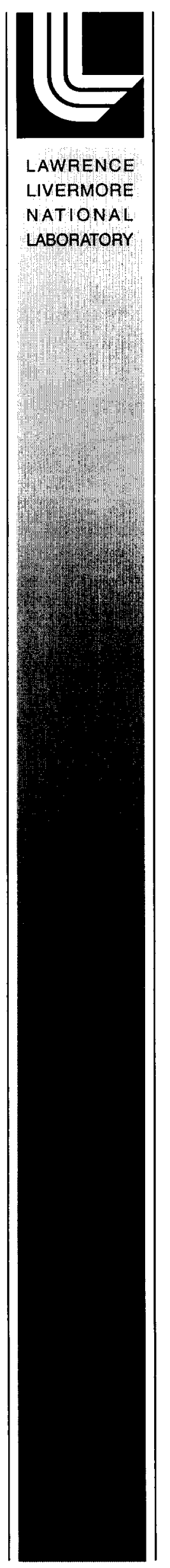

\title{
Progress in Long Scale Length Laser-Plasma Interactions
}

S.H.Glenzer, P. Arnold, G. Bardsley, R.L. Berger, G. Bonanno, T. Borger, D.E. Bower, M. Bowers, R. Bryant, S. Buckman, S.C. Burkhart, K. Campbell, M.P. Chrisp, B.I. Cohen, C. Constantin, F. Cooper, J. Cox, E. Dewald, L. Divol, S. Dixit, J.

Duncan, D. Eder, J. Edwards, G. Erbert, B. Felker, J. Fornes, G. Frieders, D.H.Froula, S. D. Gardner, C. Gates, M. Gonzalez, S. Grace, G. Gregori, A. Greenwood, R. Griffith, T. Hall, B.A. Hammel, C. Haynam, G. Heestand, M. Henesian, G. Hermes, D. Hinkel, J. Holder, F. Holdner, G. Holtmeier, W. Hsing, S. Huber, T. James, S. Johnson, O.S. Jones, D. Kalantar, J.H. Kamperschroer, R. Kauffman, T. Kelleher, J. Knight, R.K. Kirkwood, W.L. Kruer, W. Labiak, O.L. Landen, A.B. Langdon, S. Langer, D. Latray, A. Lee, F.D. Lee, D. Lund, B. MacGowan, S. Marshall, J. McBride, T. McCarville, L. McGrew, A.J. Mackinnon, S. Mahavandi, K. Manes, C. Marshall, E. Mertens, N. Meezan, G. Miller, S. Montelongo, J.D. Moody, E. Moses, D. Munro, J. Murray, J. Neumann, M. Newton, E. Ng, C. Niemann, A. Nikitin, P. Opsahl, E. Padilla, T. Parham, G. Parrish, C. Petty, M. Polk, C. Powell, I. Reinbachs, V. Rekow, R. Rinnert, B. Riordan, M. Rhodes, V. Roberts, H. Robey, G. Ross, S. Sailors, R. Saunders, M. Schmitt, M.B. Schneider, S. Shiromizu, M. Spaeth, A. Stephens, B. Still, L.J. Suter, G. Tietbohl, M. Tobin, J. Tuck, B. M. Wonterghem, R. Vidal, D. Voloshin, R. Wallace, P. Wegner, P. Whitman, E.A. Williams, K. Williams, K. Winward, K. Work, B. Young, P.E. Young, P. Zapata, R. Bahr, W. Seka, J. Fernandez, D. Montgomery, H. Rose

\section{November 11, 2003}

\author{
The Third International Conference on Inertial Fusion \\ Sciences and Applications, Monterey, California, \\ September 7-12, 2003
}


This document was prepared as an account of work sponsored by an agency of the United States Government. Neither the United States Government nor the University of California nor any of their employees, makes any warranty, express or implied, or assumes any legal liability or responsibility for the accuracy, completeness, or usefulness of any information, apparatus, product, or process disclosed, or represents that its use would not infringe privately owned rights. Reference herein to any specific commercial product, process, or service by trade name, trademark, manufacturer, or otherwise, does not necessarily constitute or imply its endorsement, recommendation, or favoring by the United States Government or the University of California. The views and opinions of authors expressed herein do not necessarily state or reflect those of the United States Government or the University of California, and shall not be used for advertising or product endorsement purposes. 


\title{
PROGRESS IN LONG SCALE LENGTH LASER-PLASMA INTERACTIONS
}

\author{
S. H. Glenzer, P. Arnold, G. Bardsley, R. L. Berger, G. Bonanno, T. Borger, D. E. Bower,
} M. Bowers, R. Bryant, S. Buckman, S. C. Burkhart, K. Campbell, M. P. Chrisp, B. I. Cohen, C. Constantin, F. Cooper, J. Cox, E. Dewald, L. Divol, S. Dixit, J. Duncan, D. Eder, J. Edwards, G. Erbert, B. Felker, J. Fornes, G. Frieders, D. H. Froula, S. D. Gardner, C. Gates, M. Gonzalez, S. Grace, G. Gregori, A. Greenwood, R. Griffith, T. Hall, B. A. Hammel, C. Haynam, G. Heestand, M. Henesian, G. Hermes, D. Hinkel, J. Holder, F. Holdner, G. Holtmeier, W. Hsing, S. Huber, T. James, S. Johnson, O. S. Jones, D. Kalantar, J. H. Kamperschroer, R. Kauffman, T. Kelleher, J. Knight, R. K. Kirkwood, W. L. Kruer, W. Labiak, O. L. Landen, A. B. Langdon, S. Langer, D. Latray, A. Lee, F. D. Lee, D. Lund, B. MacGowan, S. Marshall, J. McBride, T. McCarville, L. McGrew, A. J. Mackinnon, S. Mahavandi, K. Manes, C. Marshall, E. Mertens, N. Meezan, G. Miller, S. Montelongo, J. D. Moody, E. Moses, D. Munro, J. Murray, J. Neumann, M. Newton, E. Ng, C. Niemann, A. Nikitin, P. Opsahl, E. Padilla, T. Parham, G. Parrish, C. Petty, M. Polk, C. Powell, I. Reinbachs, V. Rekow, R. Rinnert, B. Riordan, M. Rhodes, V. Roberts, H. Robey, G. Ross, S. Sailors, R. Saunders, M. Schmitt, M. B. Schneider, S. Shiromizu, M. Spaeth, A. Stephens, B. Still, L. J. Suter, G. Tietbohl, , M. Tobin, J. Tuck, B. M. Van Wonterghem, R. Vidal, D. Voloshin, R. Wallace, P. Wegner, P. Whitman, E. A. Williams, K. Williams, K. Winward, K. Work, B. Young, P. E. Young, P. Zapata, R. Bahr*, W. Seka*, J. Fernandez**, D. Montgomery**, H. Rose**

Lawrence Livermore National Laboratory, L-399, P.O. Box 808, Livermore, CA 94551, USA.

*University of Rochester, Laboratory for Laser Energetics, Rochester, NY, USA.

** Los Alamos National Laboratory, NM, USA.

\section{Abstract}

The first experiments on the National Ignition Facility (NIF) have employed the first four beams to measure propagation and laser backscattering losses in large ignition-size plasmas. Gas-filled targets between $2 \mathrm{~mm}$ and $7 \mathrm{~mm}$ length have been heated from one side by overlapping the focal spots of the four beams from one quad operated at $351 \mathrm{~nm}(3 \omega)$ with a total intensity of $2 \times 10^{15} \mathrm{~W} \mathrm{~cm}^{-2}$. The targets were filled with 1 atm of $\mathrm{CO}_{2}$ producing of up to $7 \mathrm{~mm}$ long homogeneously heated plasmas with densities of $n_{e}=6 \times 10^{20} \mathrm{~cm}^{-3}$ and temperatures of $T_{e}=2 \mathrm{keV}$. The high energy in a $\mathrm{NIF}$ quad of beams of $16 \mathrm{~kJ}$, illuminating the target from one direction, creates unique conditions for the study of laser plasma interactions at scale lengths not previously accessible.

The propagation through the large-scale plasma was measured with a gated $x$-ray imager that was filtered for $3.5 \mathrm{keV} x$ rays. These data indicate that the beams interact with the full length of this ignition-scale plasma during the last $\sim 1$ ns of the experiment. During that time, the full aperture measurements of the stimulated Brillouin scattering and stimulated Raman scattering show scattering into the four focusing lenses of $6 \%$ for the smallest length $(\sim 2 \mathrm{~mm})$, increasing to $12 \%$ for $\sim 7 \mathrm{~mm}$. These results demonstrate the NIF experimental capabilities and further provide a benchmark for three-dimensional modeling of the laserplasma interactions at ignition-size scale lengths.

\section{INTRODUCTION}

The laser-plasma interactions in ignition hohlraums for indirect-drive inertial confinement fusion (ICF) are complex because the laser beams will propagate through a large volume of plasma before they reach the high- $Z$ walls of the hohlraum. Efficient propagation and control of undesired backscattering losses by stimulated Brillouin scattering (SBS) or stimulated Raman scattering (SRS) will be important to efficiently produce the soft $x$ rays in the high- $Z$ wall plasma for imploding the fusion capsule. The total plasma scale length will be of order $7 \mathrm{~mm}$ with electron temperatures expected to be $\mathrm{T}_{\mathrm{e}}>5 \mathrm{keV}$ and electron densities of $\mathrm{n}_{\mathrm{e}} \leq 10^{21} \mathrm{~cm}^{-3}$. Moreover, the plasma may consist of various ions species or compositions, e.g., the low-Z tamper material from the laser entrance hole, helium from the cryogenic hohlraum fill, high-Z doped capsule ablator material, 
and finally a high- $Z$ hohlraum wall consisting of gold, uranium, or a mixture of various high- $Z$ materials. Complete understanding of the propagation, absorption, and laser backscattering appears to be a paramount task, and plasma surrogates approaching these conditions may only be produced with a significant fraction of the laser energy needed for ignition experiments.

Present experimental studies of laser-plasma interactions are therefore aimed at investigating the physics processes that determine the threshold, growth, and saturation of laser backscattering losses. In particular, relevant nonlinear processes that limit the experimentally observed laser backscatter losses well below the predictions from linear theory can be studied with presently available laser capabilities. Their understanding is critically important for the development of predictive calculations of laser-plasma interactions. The ultimate goal is to develop a design tool for laser experiments in the new physics regimes available with the high energies, long laser pulses, and large scales on the National Ignition Facility (NIF) or the Laser Mega Joule (LMJ).

In previous studies, nonlinear saturation of both SBS and SRS backscattering losses has been observed with increasing laser intensities in relatively small plasmas of 1-2 mm length, e.g., at the Nova, Trident, and Omega laser facilities. Moreover, local Thomson scattering experiments on the ion waves driven by the SBS instability have also demonstrated that the wave amplitudes simultaneously saturate at small levels when approaching the saturated regime [1,2]. A number of nonlinear processes are presently being investigated to explain these observations by kinetic wave decay mechanisms or by increased wave damping and three wave de-tuning accompanied by momentum deposition or modifications of the ion or electron velocity distribution functions. To assess the applicability of these theories together with the recently developed fullscale three-dimensional modeling of laser-plasma interactions to ignition size hohlraum plasmas, we have performed SBS and SRS backscattering measurements from up to 7-mm long ignition-size plasmas on the first experiments on the National Ignition Facility.

In these experiments, the full-aperture spectrally and temporally resolved measurements show that the SBS losses into the focusing lenses saturate with increasing plasma length, and are limited to levels below $12 \%$. Simultaneous temporally and spatially resolved $\mathrm{x}-$ ray imaging further shows that the laser beams heat and propagate through the whole length of the $7 \mathrm{~mm}$-long targets. These measurements were performed with laser beams smoothed by continuous phase plates (CPP) and well-characterized beam spots, beam pointing, and synchronization allowing comparison with detailed modeling. At the large scale lengths of the experiment, the linear gain calculations and modeling with the laserplasma interaction code $\mathrm{pF} 3 \mathrm{D}$ indicate gains for SBS of 300 and for SRS of 40 accompanied by large scattering losses approaching pump depletion. The discrepancy between the experimental findings and the simulation results indicate that nonlinear saturation processes are important over the full length of an ignition target limiting the backscatter losses from parametric instabilities.

\section{EXPERIMENT ON THE NATIONAL IGNITION FACILITY}

\section{A. Target Design}

We have employed radiation hydrodynamics calculations with the code LASNEX, linear gain calculations with the code LIP, and laser propagation calculations with the code $\mathrm{pF} 3 \mathrm{D}$ to design targets suitable for studying the scaling of SBS and SRS backscattering of NIF beams in high-temperature largescale length plasmas. The same suite of codes was also employed for post-shot simulations with the laser conditions of the actual experiments for comparisons with the experimental measurements.

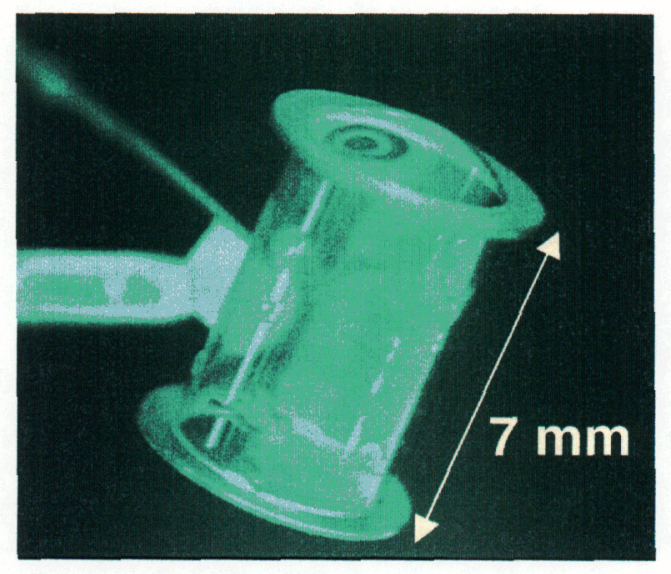

Figure 1. Gas-filled target on NIF.

The LASNEX calculations were performed to select the combination of target size, wall material, gas fill type and pressure, as well as laser pulse shape, pulse length and energy that produce long scale-length plasmas of up to $\mathrm{L} \sim 7 \mathrm{~mm}$ length, with electron temperatures of $T_{e}>2 \mathrm{keV}$, and electron densities of $n_{e}$ $\geq 0.05 n_{\mathrm{cr}}$. Here, $\mathrm{n}_{\mathrm{cr}}$ is the critical density with $\mathrm{n}_{\mathrm{cr}}=$ $10^{22} \mathrm{~cm}^{-3}$ for $3 \omega$ light. The calculations indicate that gas bags and gas pipes of $4 \mathrm{~mm}$ and $7 \mathrm{~mm}$ length filled with $1 \mathrm{~atm}$ of $\mathrm{CO}_{2}$ or $\mathrm{C}_{5} \mathrm{H}_{12}$ produce homogeneous plasmas with the desired parameters when heated by $16 \mathrm{~kJ}$ of $3 \omega$ laser light in a $3.5 \mathrm{~ns}$ long square pulse. Figure 1 shows an image of a $7 \mathrm{~mm}$ long $\mathrm{CO}_{2}$-filled target shortly before it was heated along the axis of the cylinder by the 
first four beams of the NIF. The diameter is $4 \mathrm{~mm}$ so that unconverted light at $2 \omega$ and $1 \omega$ is not illuminating the target. For all experiments, the beams (smoothed with CPPs) were focused to the center of the target.

The calculations indicate that the laser beams completely burn through the plasma at about $2 \mathrm{~ns}$ with $\sim 50 \%$ laser absorption. At that time, electron temperatures are in excess of $2 \mathrm{keV}$, ion temperatures are $0.6 \mathrm{keV}$, and there is still a significantly high electron density of $n_{e} / n_{c}>0.05$ [cf. Fig. (2)].

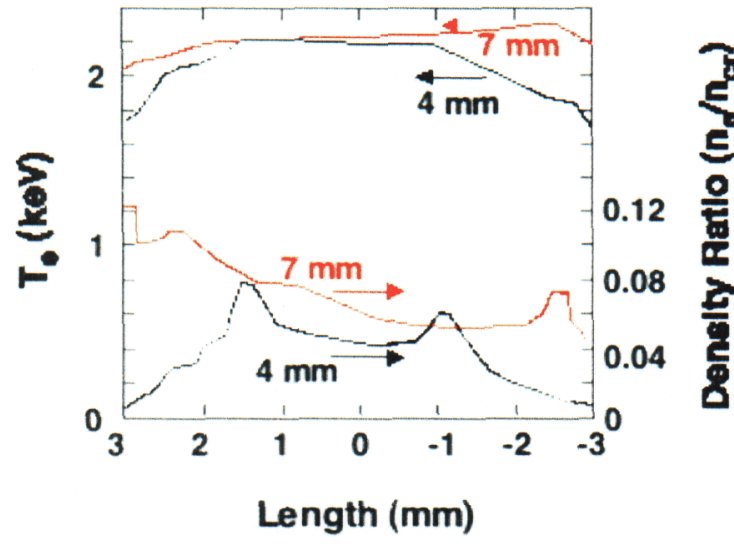

Figure 2. Calculated electron temperature and density over critical density for a $3 \omega$ beam for $4 \mathrm{~mm}$ and $7 \mathrm{~mm}$ long targets at $\mathrm{t}=2 \mathrm{~ns}$. The laser beams are propagating from the right to the left.

The scale lengths and parameters of the plasmas produced in this way approach the plasma size of future ignition experiments on NIF, and are predicted to produce large SBS and SRS gains accessing the nonlinear saturated laser backscattering regime. In this way, these plasmas are suitable platforms to test the effectiveness of laser beam smoothing by CPPs, spectral dispersion (SSD), and polarization smoothing (PS). For example, for $\mathrm{C}_{5} \mathrm{H}_{12}$ gas fills and $4 \mathrm{~mm}$ long targets, the SRS gain calculations using LIP show averaged gains of 20 over a length of $\sim 3.5 \mathrm{~mm}$, and for the $7 \mathrm{~mm}$ long target, the averaged gain value is also close to 20 but over a larger scale length of $\sim 6 \mathrm{~mm}$. The SBS gain in the $4 \mathrm{~mm}$ long target is averaging at 35 over a length of $\sim 3.5 \mathrm{~mm}$, and for the $7 \mathrm{~mm}$ long target, the averaged gain value is close to 30 but over a larger scale length of $\sim 6 \mathrm{~mm}$. Even larger gain values are obtained in $\mathrm{CO}_{2}$ filled targets with SBS gain values of 300 and SRS gains of 40 . In Section III, we will discuss the detailed comparison of LIP gain calculations with experimental backscatter spectra for the $\mathrm{CO}_{2}$ gas targets.

Fully 3-dimensional laser-plasma interaction calculations of the NIF gas target have been performed with the code $\mathrm{pF} 3 \mathrm{D}$. The calculated plasma conditions from the radiation-hydrodynamics modeling were used as input parameters over a scale length of up to $5 \mathrm{~mm}$. In addition, the $0.5 \mathrm{~mm}$ diameter CPP smoothed beam with measured NIF aberrations has been used. Calculations of up to $36 \mathrm{ps}$ have been performed (twice the light transit time). The full-volume simulations have typically 20-30\% lower SBS and SRS gain values than LIP because, in addition to inverse bremsstrahlung absorption, beam spray lowers the beam intensity after the beam has propagated approximately $2 \mathrm{~mm}$ into the plasma.

Figure 3 shows an example of the calculated laser beam propagation through the first $5 \mathrm{~mm}$ of the $7 \mathrm{~mm}$ long gas target. The laser beam absorption and beam spray is obvious in the figure. For the high gain values for SBS and SRS we find that the calculated scattering losses are highly dependent on the nonlinear model used in the simulations. If only pump depletion is included, the calculations for $\mathrm{CO}_{2}$ predict $90 \%$ backscatter over a scale length of several $100 \mu \mathrm{m}$ completely pump depleting the beam and preventing further beam propagation into the target. Initial calculations with limited ion wave amplitude, e.g., through two-ion decay, are consistent with beam propagation and scattering losses of order $20 \%$ as observed in the experiments.

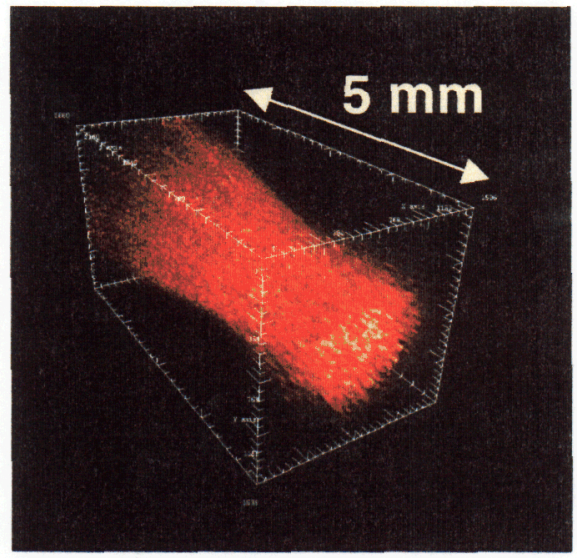

Figure 3. Fully three-dimensional pF3D calculation shows laser beam propagation through $5 \mathrm{~mm}$ long plasmas.

Nonlinear processes are also determining the relative fraction of the backscattered light into the lenses and around the lenses indicating the need to measure the so-called near backscattering. It should also be noted that the laser reflectivity quoted here are affected by the electron heating. Specifically, in these simulations, the usual pF3D nonlocal heat conduction model was used to allow heat flow transverse to the laser propagation. No heat conduction in the laser propagation direction was employed. A new Spitzer-Härm transport model is presently being developed to include this effect. 


\section{B. Beam Conditioning}

The present experiments have been performed with $500 \mu \mathrm{m}$ focal-spot CPPs providing a total intensity of $2 \times 10^{15} \mathrm{~W} \mathrm{~cm}^{-2}$ when overlapping the four beams each operated at $4 \mathrm{~kJ}$ in a $3.5 \mathrm{~ns}$ long square pulse. These CPPs are fielded on NIF in a relay plane in the front-end beam transport system (RP10). In this scheme, the beam with CPP phase aberration and a size of $4.5 \mathrm{~cm} \mathrm{x}$ $4.5 \mathrm{~cm}$ is injected into the main NIF laser chain, expanded to about $36 \mathrm{~cm} \mathrm{x} 36 \mathrm{~cm}$, and propagated through the spatial filters, large amplifiers, and the final optics onto target. Measurements of the optical focal spot in the Precision Diagnostics Station (PDS) have been performed confirming that a single beam intensity of $5 \times 10^{14} \mathrm{Wcm}^{-2}$ can be achieved for $1 \mathrm{TW}$ input power per quad. a) CPP

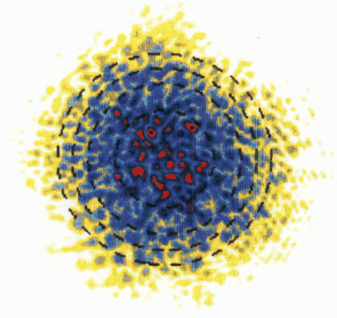

b) CPP plus SSD

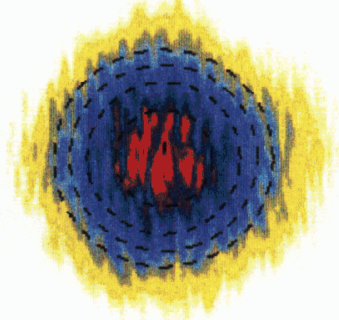

Figure 4. Measured optical focal spots of NIF beam 316 smoothed with a $500 \mu \mathrm{m}$ CPP at the RP10 position (a) and with the CPP plus $40 \mathrm{GHz}$ of SSD (b).

Figure 4 shows the measured spot at $1 \omega$ for the beam smoothed with a CPP and with a CPP plus smoothing by spectral dispersion (SSD). The measurements show that $90 \%$ of the energy is within a diameter of $540 \mu \mathrm{m}$ and $560 \mu \mathrm{m}$, respectively. The profiles match a super-Gaussian of 3-4.
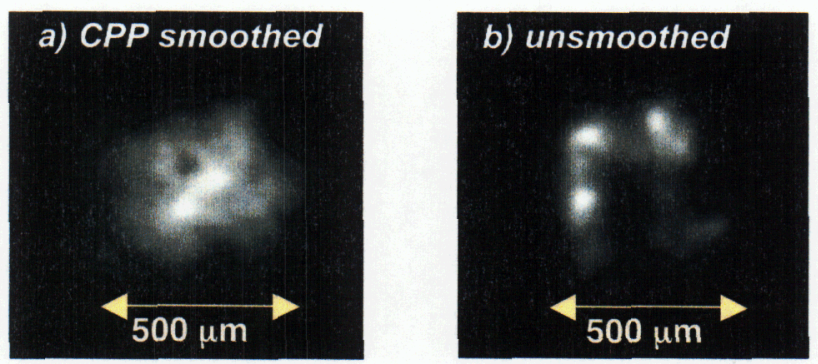

Figure 5. Measured x-ray emission from a $\mathrm{Au}$ disk irradiated by the CPP smoothed beam in the NIF target chamber (a) and by an unsmoothed beam (b).

Figure 5 shows the $\mathrm{x}$-ray emission from a gold disk irradiated by one 200-ps long CPP smoothed beam in the NIF target chamber as measured with a time- integrating Static X-ray Imager (SXI). The comparison with the unsmoothed NIF beam defocused to a $500-\mu \mathrm{m}$ spot shows clearly the improvement of the focal spot smoothness by removing multiple separate highintensity peaks. Additional improvements are expected by adding SSD. First SSD experiments have successfully been performed with a limited bandwidth of $40 \mathrm{GHz}$ testing the $17-\mathrm{GHz}$ modulator and the fm-am compensator. It is expected that a bandwidth of 150 $\mathrm{GHz}$ will be routinely fired matching the bandwidth of previous experiments on Nova that have shown suppression of backscatter losses with SSD.

\section{Diagnostics}

The interactions of the laser beams with the target have been measured with the SXI, a temporally resolving $\mathrm{X}$-ray imager $(\mathrm{FXI})$, and a Full Aperture Backscatter Station (FABS). The FXI was filtered for $3.5 \mathrm{keV} \mathrm{x}$ rays and imaged the target with a $1 \mathrm{x}$ magnification through multiple pinholes onto four gated strips of a microchannel plate detector. The strips are timed independently providing two-dimensional snap shots $(\Delta t \sim 100 \mathrm{ps})$ of the laser-generated heat wave propagating through the target.

The FABS consists of five detector systems measuring the scattered light from the target through the debris shield, final focusing optics, frequency conversion crystals, vacuum windows, and the final $1 \omega$ turning mirror. The latter points the unconverted $1 \omega$ beam to target chamber center and is coated to reflect the $1 \omega$ light but transmits SBS light at $351-352 \mathrm{~nm}$ as well as the SRS light at $450-700 \mathrm{~nm}$. The aperture of each beam line is $40 \mathrm{~cm} \mathrm{x} 40 \mathrm{~cm}$ while the each beam is operated at $33 \mathrm{~cm} \times 33 \mathrm{~cm}$. The transmission of this system to the backscattered light is of order $50 \%$ so that large aperture bare surface reflectors are used to redirect only a small fraction of the backscattered light into the horizontal direction and onto the detector tables to avoid detector damage [cf. Fig. (6)].

For each of the four beams, a calorimeter system and a calibration spectrometer system have been employed for SBS and SRS energy measurements. The calibration spectrometers measure the backscattered spectrum with time-integrating CCD cameras. The whole calibration spectrometer system has been absolutely calibrated in situ with a Xe lamp source at target chamber center resulting in a total error bar for the backscattered energy of $20 \%$. The results from the calorimeters and the calibration spectrometers agree within this error bar.

In addition to these detectors, a time-integrating speckle camera system has measured the SBS light distribution in the lens plane and a fast-photodiode system has measured the temporal shape of SBS and SRS. The latter also measured the back-reflected $3 \omega$ 
laser light and the unconverted $2 \omega$ light from the frequency conversion crystals separated by $45 \mathrm{~ns}$ from the signal off the target. This measurement allowed us to subtract the crystal reflection from the timeintegrating energy detectors or to physical block this signal on the FABS detector tables.

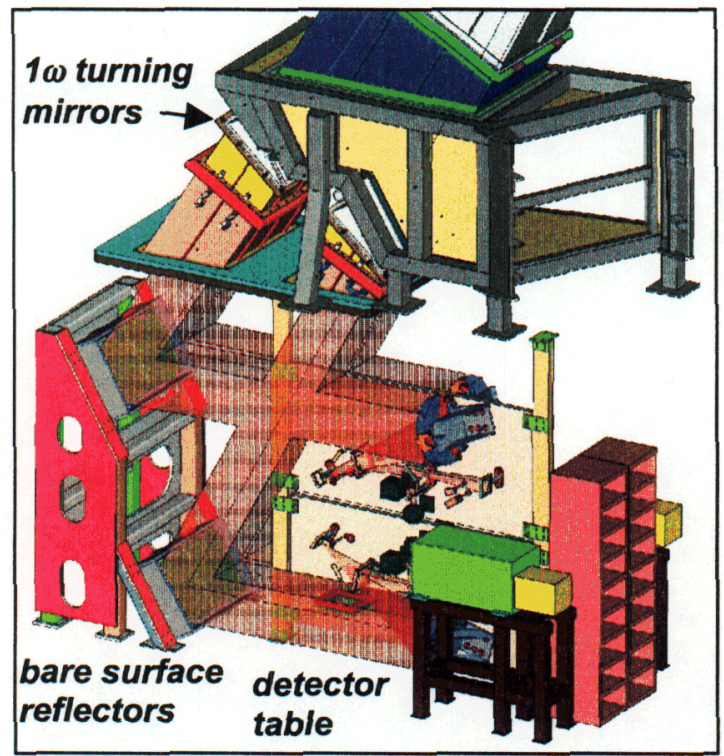

Figure 6. Schematic of the FABS Diagnostic.

At present, two streak camera-spectrometer systems are operational on one beam for detecting the SBS and SRS spectra temporally resolved with a temporal resolution of $100 \mathrm{ps}$ and spectral resolution of $0.3 \mathrm{~nm}$ for SBS and $3 \mathrm{~nm}$ for SRS. These data provide the temporal shape of the backscattered light. Normalizing the streak camera temporal signal with the measured backscattered energy from the calibration spectrometer/calorimeters allows us to infer the backscattered SBS and SRS power, which can be compared to laser-plasma interaction simulations.

\section{EXPERIMENTAL RESULTS}

Figure 7 shows LASNEX calculations and gated $\mathrm{x}$ ray emission images of the heat wave propagation at 3.5 $\mathrm{keV}$ through a $7 \mathrm{~mm}$-long $\mathrm{CO}_{2}$-filled target. In these images, the laser beams illuminate the target from the left. The inset shows an image at $t=0$ when the beams first strike the left membrane of the target with an emission region of about $500 \mu \mathrm{m}$ diameter consistent with the CPP focal spot size indicating that the four beams overlap to within $100 \mu \mathrm{m}$ in these experiments. First, the beams heat the membrane and launch a blast wave into the plasma, which is clearly visible in the images. At $\mathrm{t}=1.5 \mathrm{~ns}$, the beams have propagated about $2 / 3$ through the plasma and at $2.5 \mathrm{~ns}<\mathrm{t}<3 \mathrm{~ns}$, the beams have burned through the whole $7 \mathrm{~mm}$ plasma launching a second blast wave at the membrane on the exit side.

The calculations using the temperatures and densities shown in Sec. IIA reproduce all the essential features seen in the experiments. They slightly overestimate the propagation speed and the lateral extent of the heat wave. This may be explained by the fact that LASNEX uses a flux-limited heat transport model with a free-streaming heat flux limiter of $f=0.05$. Presently, calculations with improved heat transport models are underway to better understand these details. The experimental data and the calculations clearly indicate that the beams propagate through the whole $7 \mathrm{~mm}$ long target and interact with plasmas of a scale length equivalent to the scale future ignition hohlraums.

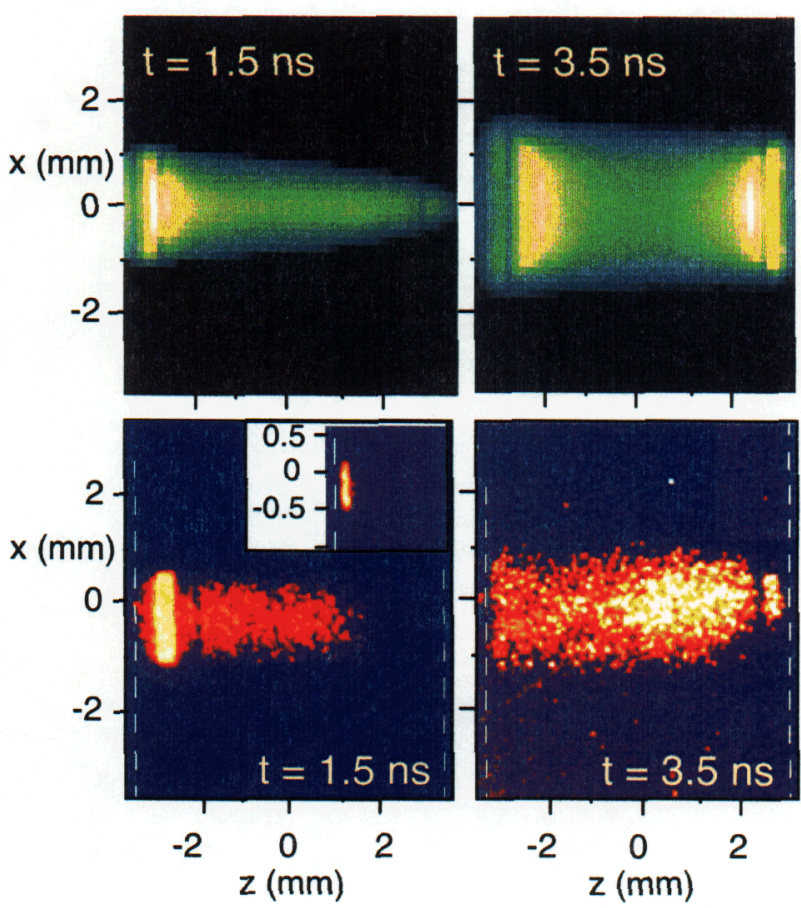

Figure 7. Side-on $x$-ray emission images at $3.5 \mathrm{keV}$ calculated with LASNEX (top) and measured with the FXI (bottom).

For the experiments with $\mathrm{CO}_{2}$-filled targets, the laser backscattering measurements show that the reflectivity is dominated by SBS. Figure 8 shows the experimental streak camera measurements of SBS and SRS as well as the LIP gain calculations as function of time. For the smallest plasma lengths investigated, i.e. $2.4 \mathrm{~mm}$ sized gas bags, the SBS reflectivity is $6 \%$, increasing to $10 \%$ for $4 \mathrm{~mm}$ long gas pipes and further increasing to $12 \%$ for $7 \mathrm{~mm}$ long targets. For all of these conditions, SRS is $0.1 \%$ or less.

The wavelength shift of the SBS spectrum is related to the electron temperature via the dispersion relation for ion acoustic waves and the SRS spectral shift 
primarily depends on the electron density via the BohmGross dispersion relation. The experimental SBS spectral shift compares well to the calculated shift that predicts the highest SBS gain for the parameters of the plateau conditions as calculated with LASNEX. The spectral shift of the SRS is slightly smaller (by $30 \mathrm{~nm}$ ) than the calculations indicating slightly lower densities than the calculations. Both the SRS and the SBS spectral widths are narrow indicating homogeneous conditions consistent with the calculations of the largescale plasma plateau where SBS and SRS are calculated to grow.

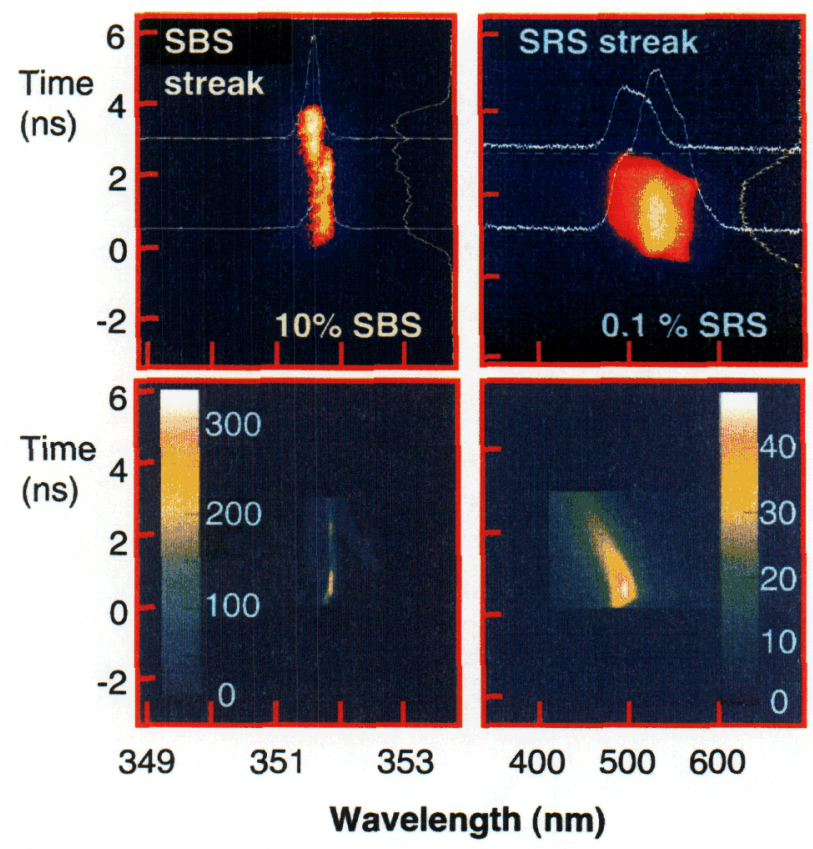

Figure 8. Experimental SBS and SRS streak camera measurements (top). SBS and SRS gains calculated using the plasma parameters from LASNEX (bottom).

Moreover, the SBS signal is large and at the $10 \%$ level throughout the laser pulse while SRS shows an initial 1-2 ns long burst and is declining to undetectable levels at the end of the heater pulse when SBS grows to its peak at $12 \%$. In addition, the SBS scattered power is orders of magnitude larger than the SRS power. The duration of the SBS and SRS as well as their relative signal levels are reproduced by the LIP calculations indicating that the plasma parameters and the spatially dependent growth rates are well understood.

On the other hand, the absolute measured SBS reflectivity into the lenses of $12 \%$ is significantly smaller than calculated by the $\mathrm{pF} 3 \mathrm{D}$ calculations. When including nonlinear hydrodynamics, nonlocal heat transport, and pump depletion as saturation mechanism we find $90 \%$ reflectivity and pump depletion of the beams within a scale length of several hundred microns.
The fact that the SBS reflectivity grows with increasing plasma length as well as the $\mathrm{x}$ ray propagation data indicate that additional nonlinear kinetic saturation mechanisms will have to be included into the simulations to reproduce the propagation and backscatter measurements [cf. Fig. (7) and (8)]. Such a model is expected to limit the amplitudes of ion acoustic fluctuations well below the pump depletion values resulting into a SBS reflectivity consistent with observations.

The present data set will provide a unique test of nonlinear kinetic models. Several possible saturation mechanisms are presently being explored for SBS such as two-ion decay, momentum deposition, and trapping. This test will require the implementation of these models into the three-dimensional code $\mathrm{pF} 3 \mathrm{D}$ for comparisons with the data. Moreover, additional measurements of the near backscatter losses around the four lenses will be required. Initial calculations have indicated that half of the total reflected light may be outside the FABS detector. These calculations are dependent on the details of the nonlinear model therefore requiring accurate measurements of this contribution.

\section{CONCLUSIONS}

The first experiment on NIF has successfully activated experimental capabilities for laser-plasma interactions studies including large scale length targets, laser beam conditioning, and gated $\mathrm{x}$-ray imaging and full-aperture backscatter diagnostics. Ignition size plasmas of up to $7 \mathrm{~mm}$ length have been investigated for the first time showing efficient propagation and limited backscattering losses of $12 \%$ into the focusing lenses. The data set will provide a benchmark for threedimensional calculations of laser-plasma interactions with the goal to develop predictive calculations for designing experiments on NIF or LMJ.

This work was supported by LDRD ${ }^{\#} 01$-ERD-107 and was performed under the auspices of the U.S. Department of Energy by the University of California, Lawrence Livermore National Laboratory under Contract No. W-7405-ENG-48.

\section{References}

[1] S. H. Glenzer, L. M. Divol, R. L. Berger, C. Geddes, R. K. Kirkwood, J. D. Moody, E. A. Williams, and P. E. Young, "Thomson scattering measurements of saturated ion waves in laser fusion plasmas", Phys. Rev. Lett. 86, 2565 (2001).

[2] D. H. Froula, L. Divol, and S. H. Glenzer, "Measurements of Nonlinear growth of Ion-Acoustic Waves in Two-Ion-Species Plasmas with Thomson Scattering", Phys. Rev. Lett. 87, 045002 (2002). 